\title{
Assessment of antioxidant and xanthine oxidase inhibitory activity of Triadica cochinchinensis stem bark
}

\author{
Carla Wulandari Sabandara,*, Juriyati Jalilb, Norizan Ahmatc, Nor-Ashila Aladdin ${ }^{b}$ \\ aDepartment of Pharmacy, Faculty of Science and Technology, Universitas Sembilanbelas November Kolaka, Kolaka, Indonesia 93517 \\ bDrug and Herbal Research Centre, Faculty of Pharmacy, Universiti Kebangsaan Malaysia, Kuala Lumpur, Malaysia 503000 \\ 'Faculty of Applied Sciences, Universiti Teknologi MARA, Shah Alam, Selangor, Malaysia 40450
}

\section{ABSTRACT}

Triadica cochinchinensis has been used traditionally to treat diseases related to oxidative stress. Nonetheless, little is known about its biological activity. This study aimed to evaluate the antioxidant and xanthine oxidase inhibitory activity of this plant. For this purpose, qualitative phytochemicals, total phenolic, total flavonoid, antioxidant assays (DPPH and FRAP), and xanthine oxidase assay were evaluated towards methanol and organic fractions of its stem bark. Results showed the occurrence of flavonoids, tannins, terpenoids, steroids, and saponins in the methanol extract. The extract and its two fractions (ethyl acetate and methanol) exhibited promising radical scavenging (IC50 values between 3.6-4.5 $\mu \mathrm{g} / \mathrm{mL}$ ) and ferric reduction activities (4.2-5.5 $\mu \mathrm{g} / \mu \mathrm{g}$ of equivalent trolox amount). They also exhibited inhibition on the xanthine oxidase activity ranging from 43.8 to $80.5 \%$ at a dose of $100 \mu \mathrm{g} / \mathrm{mL}$. These activities could be attributed to the amount of phenolics in the methanol extract and active fractions (136.6-174.1 $\mathrm{mg} \mathrm{GAE} / \mathrm{g}$ of sample). Our results suggested that the methanol extract of $T$. cochinchinensis stem bark could be used as a promising source of lead molecules for antioxidant and xanthine oxidase inhibitors from natural source.
Article history:

Received 1 Jul 2019

Revised 7 Aug 2019

Accepted 9 Aug 2019

Available online 30 Aug 2019

Keywords:

Triadica cochinchinensis

Sapium discolour

Euphorbiaceae

antioxidant

Xanthine oxidase

*Corresponding author:

cw.sabandar@gmail.com

\section{Introduction}

The genus Triadica is a small genus belongs to the family Euphorbiaceae and is endemic to the east and southeast Asia (Esser, 2002). This genus grows as trees or shrubs and so far has only three accepted species according to The Plant List, which are Triadica cochinchinensis Lour, $T$. rotundifolia (Hemsl.) Esser, and T. sebifera (L.) Small (The Plant List, 2013). Species $T$. cochinchinensis previously classified under the genus Sapium and named as Sapium discolor (Champ. ex Benth.) Müll.Arg.). However, due to some circumstances, this species has recently recognised under the genus Triadica. This species can grow up to $25 \mathrm{~m}$ tall tree and it is available widely throughout India, Thailand, and Indochina to China. It also can be found in the Kalimantan, Sulawesi, and the Philippines (Esser, 2002). Different parts of $T$. cochinchinensis are used traditionally as folk medicine. In Malaysia, the plant is used to treat gastrointestinal worms and consumed as a good protein source (Wan Zahari et al., 2007). In the traditional Chinese medicine (TCM), root and leaf of this plant are mainly used to treat constipation, dysuria, dermatitis, herpes, mastitis, eczema, edema, wounds, and snake bites (Lai et al., 2004). The preparations of both parts of the plant also applied to alleviate nephritis and cirrhosis (Liu et al., 2015). Despite its medicinal values, scientific knowledge about biological activity and chemistry of this plant still needs more paces. Recently, the plant has been reported to contain diterpenoids, phenolics, triterpenoids, coumarinolignoids, and lignoids from leaf and stem parts. Their biological activities include anticancer activity and nitric oxide inhibition in BV-2 microglial cells induced by lipopolysaccharide (Liu et al., 2015; Zhang et al., 2018; Zhang et al., 2019). In this study, the antioxidant and xanthine oxidase inhibition of the stem bark of $T$. cochinchinensis were evaluated with the purpose of adding new knowlegde on this plant.

\section{Materials and Methods}

\subsection{General}

Analytical solvents (petroleum ether, ethyl acetate, and methanol), Folin-Ciocalteu's reagent, aluminium chloride, sodium carbonate, hydrochloric acid, potassium dihydrogen phosphate were bought from Merck (Darmstadt, Germany). Dimethyl sulphoxide, diphenyl-picryhydrazyl (DPPH), $\mathrm{FeCl}_{3} .6 \mathrm{H}_{2} \mathrm{O}$, 2,4,6-tri(2-pyridyl-s-triazine) (TPTZ), xanthine (99\% purity), and the positive controls (ascorbic acid, quercetin, trolox, gallic acid, and allopurinol) were obtained from SigmaAldrich (St. Louis, MO. USA). Sodium acetate trihydrate and acetic acid (glacial) were purchased from R \& M Chemicals and Friendmann Schimdt (Parkwood, WA, Australia), respectively. Xantine oxidase was purchased from Roche (Penzberg, Germany). Flat bottom 96 well microplates (UV-Star, $\mu$ Clear) were purchased from Greiner Bio One (Frickenhausen, Germany). Absorbance reading was carried 
out using a Thermo Multiskan Go microplate reader (Waltham, MA, USA).

\subsection{Plant sample}

The stem bark of $T$. cochinchinensis was collected from Pahang, Malaysia in August 2012. Sample specimen was identified by a botanist from the Universiti Putra Malaysia and deposited at the Universiti Teknologi MARA. The collected part was cleaned with distilled water and drained. Sample was further cut into small parts. The water content of this sample was removed using an oven at $40^{\circ} \mathrm{C}$, and the dried sample was coarsely powdered using a grinder.

\subsection{Extraction and fractionation}

The dried powdered stem bark of $T$. cochinchinensis $(500$ g) was macerated thrice with methanol ( $3 \mathrm{~L})$ for $24 \mathrm{hr}$. The extract was filtered using a Büchner funnel apparatus and then concentrated using a vacuum evaporator, resulting in a dried extract (98 g). A 10-gram portion of this extract was redissolved in methanol and partitioned successively with petroleum ether and ethyl acetate using a separating funnel. Solvents were then evaporated to obtain filtrates of petroleum ether (FPe), ethyl acetate (FEa), and remaining methanol (FMe) fractions. All extracts and organic fractions were stored in amber bottles and kept in a refrigerator at $4^{\circ} \mathrm{C}$.

\subsection{Phytochemical screening}

Phytochemicals of the extract of $T$. cochinchinensis stem bark were qualitatively screened for alkaloids, flavonoids, tannins, terpenoids, steroids, and saponins according to previous methods by Ayoola et al. (2008) and Nobakht et al. (2010).

\subsection{Total phenolic content estimation}

The amount of phenolics in the extract of $T$. cochinchinensis stem bark was estimated in accordance to the Folin-Ciocalteu's method converted into a micromethod (ISO $14502-1,2005)$. Twenty- $\mu \mathrm{L}$ of samples $(0.1 \mathrm{mg} / \mathrm{mL}$ in DMSO) was added with Folin-Ciocalteu's reagent $(100 \mu \mathrm{L}$, $10 \%$ ) in the 96-well plates and let to $5 \mathrm{~min}$ of incubation at ambient temperature. After incubation, the mixture was added with $\mathrm{Na}_{2} \mathrm{CO}_{3}$ solution ( $\left.80 \mu \mathrm{L}, 75 \%\right)$, slightly shaken, and re-incubated for $30 \mathrm{~min}$ in dark at ambient temperature. The absorbance $(735 \mathrm{~nm})$ was recorded using a microplate reader against a sample blank containing only sample and solvent. A linear calibration curve of a phenolic compound, gallic acid was plotted for the absorbance versus their respective concentrations of standard solutions (10-100 $\mu \mathrm{g} / \mathrm{mL})$. The amount of phenolics in the methanol extract and organic fractions was calculated as $\mathrm{mg}$ of gallic acid equivalent (GAE).

\subsection{Total flavonoid content estimation}

The amount of flavonoids the extract of $T$. cochinchinensis stem bark was estimated based on the aluminum calorimetric method with some adaptations (Yang et al., 2011). One hundred- $\mu \mathrm{L}$ of samples $(0.1 \mathrm{mg} / \mathrm{mL}$ in
DMSO) was added with $\mathrm{AlCl}_{3}$ solution $(100 \mu \mathrm{L}, 2 \%)$ in the 96-well plates and let for $15 \mathrm{~min}$ of incubation at ambient temperature. The absorbance (435 nm) was recorded using a microplate reader against a sample blank containing only sample and solvent. A linear calibration curve of quercetin was plotted for the absorbance versus their respective concentrations of standard solutions $(10-100 \mu \mathrm{g} / \mathrm{mL})$. The amount of flavonoids in the methanol extract and fractions was expressed as $\mathrm{mg}$ of quercetin equivalent (QE).

\subsection{DPPH assay}

The DPPH scavenging activity of extract and fractions of T. cochinchinensis stem bark was evaluated using diphenylpicrylhydrazyl (DPPH) method with slight modification (Clarke et al., 2013). Samples and positive controls (ascorbic acid, trolox, gallic acid, and quercetin) were prepared within concentration ranges of $1.56-100 \mu \mathrm{g} / \mathrm{mL}$ in DMSO. One hundred- $\mu \mathrm{L}$ of samples was added with DPPH solution (100 $\mu \mathrm{L}, 10 \%)$ in the 96-well plates and let for $15 \mathrm{~min}$ of incubation at ambient temperature. The absorbance (540 $\mathrm{nm}$ ) was measured using a microplate reader against a sample blank containing only sample and solvent. The percentage of scavenging activity (\%SA) of DPPH radical was determined as follows: \%SA $=\left[\left(A_{b}-A_{s}\right) / A_{b}\right] \times 100$. The $A_{b}$ was the control absorbance and $A_{s}$ was the sample absorbance after sample blank correction. The $\mathrm{IC}_{50}$ values of active samples were analysed using the GraphPad Prism 5.

\subsection{FRAP assay}

The ferric reducing antioxidant power activity was evaluated in accordance to Benzie and Strain (1996) converted into a micromethod (Yang et al., 2011). The FRAP reagent prepared freshly, consisting of acetate buffer (300 $\mathrm{mM}$, pH 3.6), TPTZ solution (10 mM in $40 \mathrm{mM}$ hydrochloric acid) and ferric chloride solution (20 mM) (10:1:1, v/v/v). Twenty- $\mu \mathrm{L}$ of samples (100 $\mu \mathrm{g} / \mathrm{mL}$ in DMSO) was transferred into the 96-wells plate and added with $180 \mu \mathrm{L}$ of FRAP reagent. The mixture was shaken for 10 seconds and let to 4 min of incubation at $37^{\circ} \mathrm{C}$. The absorbance $(593 \mathrm{~nm})$ was measured using a microplate reader against a sample blank containing only sample and solvent. Ascorbic acid, gallic acid, and quercetin were used as standards of active reductors. A linear calibration curve of trolox was plotted for the absorbance versus concentration of corresponding trolox solutions $(0.78-100 \mu \mathrm{g} / \mathrm{mL})$.

\subsection{Xanthine oxidase assay}

The inhibition of xanthine oxidase activity was evaluated based on the previous method by Seruji et al. (2012) with a slight modification. Sample stock solutions $(20 \mathrm{mg} / \mathrm{mL})$ and allopurinol (10 mg/mL) were prepared in DMSO and diluted with phosphate buffer ( $\mathrm{pH}$ 7.5) to obtain $2.5 \mathrm{mg} / \mathrm{mL}$ of working solutions. A $10-\mu \mathrm{L}$ of working solutions were transferred into the 96-wells plate and added with $130 \mu \mathrm{L}$ of phosphate buffer and $10 \mu \mathrm{L}$ of xanthine oxidase solution $(0.2$ unit $/ \mathrm{mL}$ ), and let to $15 \mathrm{~min}$ of incubation at $25^{\circ} \mathrm{C}$. After incubation, $100 \mu \mathrm{L}$ of xanthine solution ( $0.15 \mathrm{mM}$, $\mathrm{pH} 7.5)$ 
was added into each well and re-incubated for $10 \mathrm{~min}$ at $25^{\circ} \mathrm{C}$. The absorbance $(295 \mathrm{~nm})$ was measured using a microplate reader. The percentage inhibition (\%I) was calculated as follows: \%I $=1-[(\mathrm{A}-\mathrm{B})-(\mathrm{C}-\mathrm{D}) /(\mathrm{A}-\mathrm{B})] \times 100$, where $\mathrm{A}$ is the absorbance of $\mathrm{XO}$ without sample, $\mathrm{B}$ is the absorbance of blank without $\mathrm{XO}$ and sample, $\mathrm{C}$ is the absorbance of XO and sample, and D is the absorbance of sample without XO.

\subsection{Statistical analysis}

Data of assays were obtained from three replicates and presented as mean \pm standard deviation (SD). Statistical analysis of the data was performed using the GraphPad Prism 5.01 for Windows (GraphPad Software Inc., California, USA). One-way ANOVA followed by Tukey's test was used to compare the differences among groups $(\mathrm{p}<0.05$ represented a significant difference). The correlation between parameters was evaluated using Pearson analysis.

\section{Results and Discussion}

Maceration of the dried powdered stem bark of $T$. cochinchinensis using methanol yielded a brown gum of extract with a percentage yield of $19.6 \%$, implying a high content of polar compounds in this extract. Hence, the use of methanol for compounds extraction of $T$. cochinchinensis stem bark was considered effective. However, considering the toxicity of methanol, further studies regarding cell-based in vitro and in vivo assays should employ less toxic solvents like ethanol, hydroethanol, and water for more safe purpose (Kraut and Mullins, 2018).

Phytochemical screening qualitatively showed the presence of flavonoids, tannins, terpenoids, steroids, and saponins in the methanol extract of $T$. cochinchinensis stem bark (Table 1). On the other hand, alkaloids were absent in this extract. Recent studies on the chemistry of $T$. cochinchinensis have shown the occurrence of terpenoids from the leaf and stem, including diterpenoids and triterpenoids (Liu et al., 2015; Zhang et al., 2018). In addition, coumarinolignoids and lignoids also were reported from the same parts of this plant (Zang et al., 2018; Zhang et al., 2019). The presence of these phytochemicals has been known as a feature of the genus from the family Euphorbiaceae, including Croton, Jatropha, and Sapium (Salatino et al., 2007; Sabandar et al., 2013; Al Muqarrabun et al., 2014). Estimation of amount of phenolics and flavonoids demonstrated that the stem bark of $T$. cochinchinensis contained more than $10 \%$ of phenolics for each gram of the methanol extract and of this, about $3 \%$ of the content are flavonoids (Table 2).
Table 1. Qualitative phytochemicals of the methanol extract of $T$. cochinchinensis stem bark.

\begin{tabular}{lc}
\hline Phytochemicals & Remark \\
\hline Alkaloids & - \\
Flavonoids & + \\
Tannins & + \\
Terpenoids & + \\
Steroids & + \\
Saponins & + \\
\hline
\end{tabular}

The distribution of phenolics in the organic fractions of this extract was in a solvent-dependent manner and the amounts were found to decrease in order of methanol (FMe) $>$ ethyl acetate (FEa) > petroleum ether (FPe) fractions. Meanwhile, flavonoids in the ethyl acetate and methanol fractions were in comparable amounts $(\mathrm{p}>0.05)$ that are 31.85 and $30.86 \mathrm{mg} \mathrm{QE} / \mathrm{g}$, respectively. On the other hand, the petroleum ether fraction contained the least amount of flavonoids with a total of $16.21 \mathrm{mg} \mathrm{QE} / \mathrm{g}$. Our results indicated that the presence of phenolics and flavonoids in the methanol extract and organic fractions of the stem bark of this plant played a significant role to exhibit the antioxidant activity. A previous study has reported the effectiveness of methanol to extract antioxidant compounds (Ngo et al., 2017). The extract and its two fractions (ethyl acetate and methanol fractions) contained high amounts of phenolics and flavonoids and exhibited a significant DPPH radical scavenging activity $(\mathrm{p}<0.05)$ as compared to the petroleum ether fraction that contained the least amounts of both types of compounds (Tables 2 and 3).

Table 3. Percentage scavenging activity and $\mathrm{IC}_{50}$ values of methanol extract and organic fractions of $T$. cochinchinensis stem bark towards DPPH radical.

\begin{tabular}{lll}
\hline \multirow{2}{*}{ Extract/fractions } & \multicolumn{2}{c}{ DPPH } \\
\cline { 2 - 3 } & $\begin{array}{c}\text { SA }(\%) \text { at } 100 \\
\mu \mathrm{g} / \mathrm{mL}\end{array}$ & IC $_{50}(\mu \mathrm{g} / \mathrm{mL})$ \\
\hline ME & $80.2 \pm 0.5^{\mathrm{a}}$ & $3.6 \pm 0.1^{\mathrm{a}}$ \\
$\mathrm{FPe}$ & $55.3 \pm 0.5^{\mathrm{b}}$ & $16.1 \pm 0.03^{\mathrm{b}}$ \\
FEa & $85.5 \pm 0.6^{\mathrm{c}}$ & $3.7 \pm 0.2^{\mathrm{a}}$ \\
FMe & $85.2 \pm 0.4^{\mathrm{c}}$ & $4.5 \pm 0.1^{\mathrm{c}}$ \\
Ascorbic acid & $94.9 \pm 1.5^{\mathrm{d}}$ & $1.5 \pm 0.4^{\mathrm{d}}$ \\
Trolox & $90.3 \pm 0.1^{\mathrm{e}}$ & $2.5 \pm 0.01^{\mathrm{e}}$ \\
Gallic acid & $91.1 \pm 0.05^{\mathrm{e}}$ & $1.4 \pm 0.02^{\mathrm{d}}$ \\
Quercetin & $65.0 \pm 0.1^{\mathrm{f}}$ & $3.8 \pm 1.0^{\mathrm{a}, \mathrm{c}}$ \\
\hline
\end{tabular}

Values with different superscript letter (a, b, c, d, e, f) on the same column are significantly different $(\mathrm{p}<0.05)$ as measured by Tukey's test.

Pearson analysis showed a strong correlation between the amount of phenolics and radical scavenging activity of methanol extract and fractions at $100 \mu \mathrm{g} / \mathrm{mL}(\mathrm{r}=-0.95277$; $\mathrm{p}=0.0472$ ) (Table 4). The higher phenolics content was presented in the samples, the lower IC 50 values was achieved $(\mathrm{r}=-0.95277)$.

Table 2. Yield, total phenolic content (TPC) and total flavonoid content (TFC) of methanol extract and organic fractions of T. cochinchinensis stem bark.

\begin{tabular}{lcccc}
\hline \multicolumn{1}{c}{ Extract/fractions } & Code & Yield $(\mathrm{g})$ & TPC $(\mathrm{mg} \mathrm{GAE} / \mathrm{g})$ & TFC $(\mathrm{mg}$ QE/g) \\
\hline Methanol extract & ME & 98 & $136.6 \pm 2.4^{\mathrm{a}}$ & $50.0 \pm 4.6^{\mathrm{a}}$ \\
Petroleum ether fraction & FPe & 0.2 & $33.5 \pm 0.3^{\mathrm{b}}$ & $16.2 \pm 2.2^{\mathrm{b}}$ \\
Ethylacetate fraction & FEa & 1.8 & $154.7 \pm 1.7^{\mathrm{c}}$ & $31.9 \pm 2.0^{\mathrm{c}}$ \\
Methanol fraction & FMe & 7.9 & $174.1 \pm 2.4^{\mathrm{d}}$ & $30.9 \pm 2.2^{\mathrm{c}}$ \\
\hline
\end{tabular}


Table 4. Pearson correlation ( $\mathrm{r}$ ) and linear curve correlation ( $\mathrm{r}^{2}$ ) of total phenolic content (TPC) and total flavonoid content (TFC) towards DPPH scavenging activity $\left(\mathrm{IC}_{50}\right)$, FRAP, and XO inhibition.

\begin{tabular}{lcccccc}
\hline \multirow{2}{*}{ Content } & \multicolumn{2}{c}{ DPPH $\left(\right.$ IC $\left._{50}\right)$} & \multicolumn{2}{c}{ FRAP activity } & \multicolumn{2}{c}{ XO inhibition } \\
\cline { 2 - 6 } & Pearson $\mathrm{r}$ & $\mathrm{r}^{2}$ & Pearson $\mathrm{r}$ & $\mathrm{r}^{2}$ & Pearson $\mathrm{r}$ & $\mathrm{r}^{2}$ \\
\hline TPC & $-0.95277^{\mathrm{a}}$ & 0.90778 & $+0.99925^{\mathrm{a}}$ & 0.99849 & +0.78443 & 0.61533 \\
TFC & -0.79750 & 0.63600 & +0.59720 & 0.35660 & +0.11650 & 0.01358 \\
\hline \multicolumn{3}{c}{} \\
\end{tabular}

On the other hand, the content of flavonoids was considered not significant towards DPPH scavenging activity ( $\mathrm{r}=-0.79750, \mathrm{p}=0.2025$ ). It is known that phenolics and flavonoids have been highlighted as the major determinants of antioxidant activities in plants and foods (Heim et al., 2002). However, good antioxidant activities do not always represent by the large amounts of phenolics and flavonoids (Yang et al., 2011) This can be seen by the lowest $\mathrm{IC}_{50}$ value of the methanol extract to scavenge the free radical as compared to its ethyl acetate (FEa) and methanol fractions (FMe) that contained more phenolics. Indeed, the $\mathrm{IC}_{50}$ values of the methanol extract and ethyl acetate fraction (FEa) were considered lower than that of pure quercetin $\left(\mathrm{IC}_{50} 3.8\right.$ $\mu \mathrm{g} / \mathrm{mL})$. Nonetheless, their $\mathrm{IC}_{50}$ values were comparable statistically. Hence, this indicated a synergistic effect with other entities in the extract and fractions. Their scavenging activities were increased in dose-dependent manner that could be observed at concentration of 1.56 to $100 \mu \mathrm{g} / \mathrm{mL}$ (Figure 1).

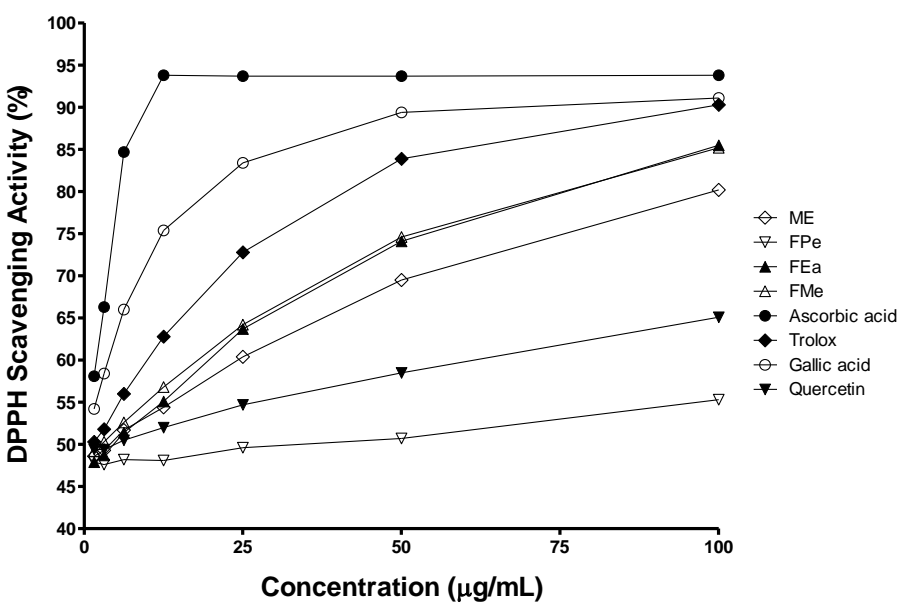

Fig. 1. DPPH scavenging activity of methanol extract, organic fractions of T. cochinchinensis stem bark, ascorbic acid, trolox, gallic acid, and quercetin.

Moreover, the FRAP values of methanol extract and its organic fractions were consistent with the free radical scavenging activity (Figure 2). This ferric reduction activity of the extract had been shown to be positively correlated with the phenolic content $(r=0.99925 ; \mathrm{p}=0.0008)$ than flavonoid content $(r=0.59720 ; p=0.4028)$, suggesting the presence of active reductive phenolics. However, their activity was comparatively lower than pure gallic acid and quercetin $(\mathrm{p}<0.05)$ despite high contents of phenolics and flavonoids. This might be due to the presence of other entities, especially the non-reductive compounds like triterpenoids. Plants provide a remarkable source of natural

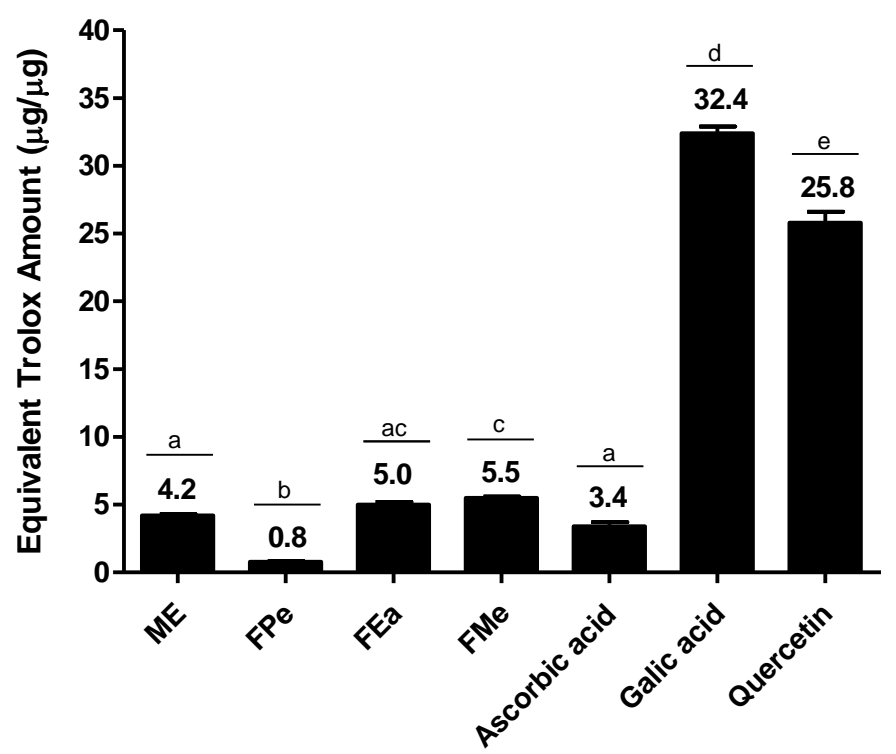

Fig. 2. FRAP activity activity of methanol extract and organic fractions of T. cochinchinensis stem bark. Bars with different letter (a, b, c, d, e) are significantly different $(\mathrm{p}<0.05)$ as measured by Tukey's test.

antioxidants that may function as free radical scavengers, reducing agents, prooxidant metals chelators, and singlet oxygen quenchers (Prat, 1992). Due to these functions, natural antioxidants from plants have been associated with improving health and providing protection from diseases, gaining research interests from both scientists and food manufacturers (Löliger, 1991). Species of the family Euphorbiaceae have shown potent antioxidant activity assayed using in vitro and in vivo models (Salatino et al., 2007; Sabandar et al., 2013; Al Muqarrabun et al., 2014). To our knowledge, the antioxidant activity of $T$. cochinchinensis is firstly reported in the present study. Xanthine oxidase (XO) is an enzyme crucialy involved in the purines catabolism in humans. This enzyme converts hypoxanthine to xanthine followed by conversion of xanthine to form uric acid, which is an end-product released by kidneys. During this conversion, reactive oxygen species (ROS) also produced, such as superoxide radical anion and hydrogen peroxide (Kostić et al., 2015). In addition, the overactivity of XO leads to the excess level of uric acid in blood plasma which has been associated with the development of gout and renal disorders (El Ridi and Tallima, 2017). Research on XO has been developed to identify potent XO inhibitors from nature including plants since the current treatment has presented with unwanted side effects (Burns and Wortmann, 2012). Based on our results, the extract of $T$. cochinchinensis stem bark was weakly active in inhibiting XO activity as compared to allopurinol $(\mathrm{p}<0.05)$ (Figure 3$)$. 


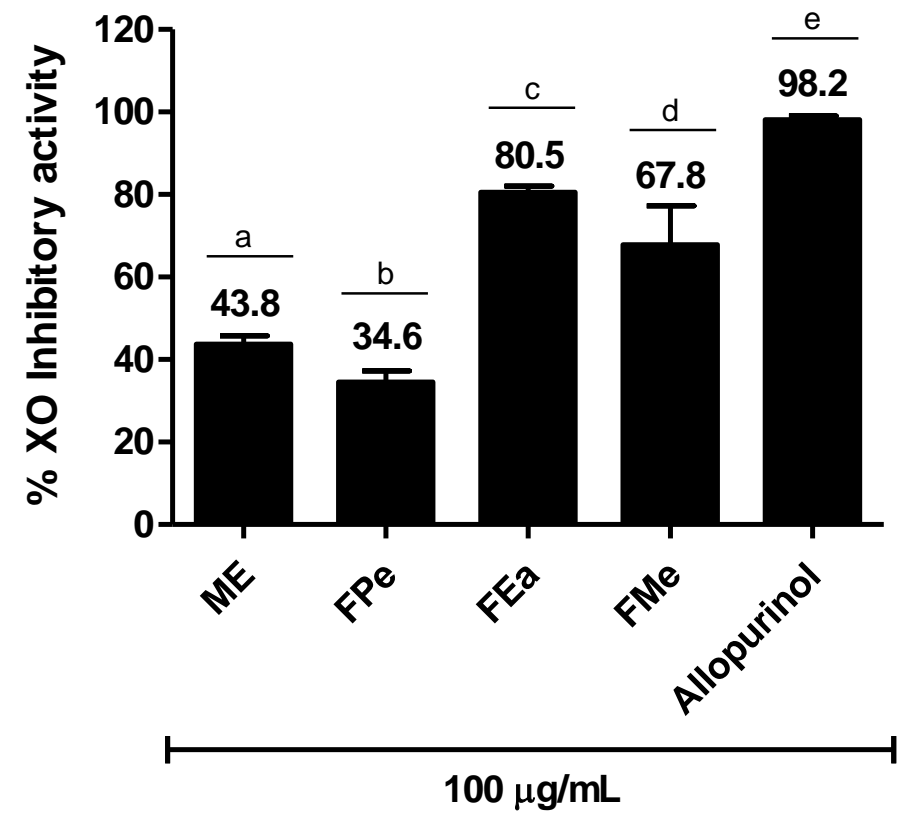

Fig. 3. Xanthine oxidase inhibitory activity of methanol extract and organic fractions of $T$. cochinchinensis stem bark. Bars with different letter (a, b, c, $\mathrm{d}, \mathrm{e})$ are significantly different $(\mathrm{p}<0.05)$ as measured by Tukey's test.

Previous studies have reported a similar trend of XO inhibition by Euphorbiaceae plants, such as Euphorbia characias, E. formosana, and E. hirta (Fais et al., 2018; Chen et al., 2009; Bangou et al., 2011). Nonetheless, the ethyl acetate and methanol fractions of this plant exhibited a promising XO inhibitory activity with inhibitions of $80.5 \%$ in FEa and $67.8 \%$ in FMe, respectively at a dose of $100 \mu \mathrm{g} / \mathrm{mL}$. Pearson analysis indicated that the presence of phenolics might give a handful contribution for this activity $(\mathrm{r}=$ 0.78443; $p=0.2156$ ). In contrast, the correlation between the amount of flavonoids and XO inhibitory activity was considered not significant $(r=0.11650 ; p=0.8835)$. Nonetheless, some compounds from these groups have been reported as XO inhibitors (Kostić et al., 2015). Therefore, our results suggested that phenolics from the stem bark of $T$. cochinchinensis might be a potential for XO inhibitory activity.

\section{Conclusion}

Our results concluded that methanol extract and organic fractions (ethyl acetate and methanol) of the stem bark of T. cochinchinensis demonstrated promising antioxidant and xanthine oxidase inhibitory activities. The presence of chemical compounds, in particular, phenolics might be a potential source of bioactive molecules from this plant. Hence, further studies are required substantially to discover the potential of this plant for its use in drugs development from natural sources.

\section{Author Contributions}

C.W.S. performed research experiments, data analysis, and manuscript preparation. ; J.J. contributed to the research design and facilitated the research, including chemicals and instrumentation; N.A. contributed to the research design, plant sample collection, and identification; N.-A.A assisted and performed XO bioassay as well as analyzed the data.

\section{Conflict of Interest}

All authors declare no conflict of interests would arise from this study.

\section{References}

Al Muqarrabun LMR, Ahmat N, Aris SRS. 2013. A review of the medicinal uses, phytochemistry and pharmacology of the genus Sapium $J$ Ethnopharmacol 155:9-20. DOI: 10.1016/j.jep.2014.05.028

Ayoola GA, Coker HA, Adesegun SA, Adepoju-Bello AA, Obaweya K, Ezennia EC, Atangbayila TO. 2008. Phytochemical screening and antioxidant activities of some selected medicinal plants used for malaria therapy in southwestern Nigeria. Trop J Pharm Res 7(3):1019-1024. DOI: 10.4314/tjpr.v7i3.14686

JeanBangou M, Kiendrebeogo M, Meda NT, Coulibaly AY. 2011. Evaluation of enzymes inhibition activities of medicinal plant from Burkina Faso. Pak J Biol Sci 14(2):99-105. DOI: 10.3923/pjbs.2011.99.105

Benzie IFF, Strain JJ. 1996. The ferric reducing ability of plasma (FRAP) as a measure of "antioxidant power": the FRAP assay. Anal Biochem 239:706. DOI:10.1006/abio.1996.0292

Burns CM, Wortmann RL. 2012. Latest evidence on gout management: what the clinician needs to know. Ther Adv Chronic Dis 3(6):271-86. DOI: $10.1177 / 2040622312462056$

Chen CH, Chan HC, Chu YT, Ho HY, Chen PY, Lee TH, Lee CK. 2009. Antioxidant activity of some plant extracts towards xanthine oxidase, lipoxygenase and tyrosinase. Molecules 14:2947-58. DOI: 10.3390/molecules14082947

Clarke G, Ting K, Wiart C, Fry J. 2013. High correlation of 2,2-diphenyl-1picrylhydrazyl (DPPH) radical scavenging, ferric reducing activity potential and total phenolics content indicates redundacy in use of all three assays to screen for antioxidant activity of extracts of plants from the Malaysian rainforest. Antioxidant 2:1-10. DOI 10.3390/antiox2010001

El Ridi R, Tallima H. 2017. Physiological functions and pathogenic potential of uric acid: a review. $J$ AdV Res 8:487-93. DOI: 10.1016/j.jare.2017.03.003

Esser H-J. 2002. A revision of Triadica Lour. (Euphorbiaceae). Harv Pap Bot 7:17-21.

Fais A, Era B, Di Petrillo A, Floris S, Piano D, Montoro P, Tuberoso CI, Medda R, Pintus F. 2018. Selected enzyme inhibitory effects of Euphorbia characias extracts. BioMed Res Int 1219367. DOI: 10.1155/2018/1219367

Heim KE, Tagliaferro AR, Bobilya DJ. 2002. Flavonoid antioxidants: chemistry, metabolism and structure-activity relationships. $J$ Nutr Biochem 13:572-84. DOI: 10.1016/S0955-2863(02)00208-5

ISO 14502-1. 2005. Determination of substances characteristic of green and black tea. Part 1: content of total polyphenols in tea-colorimetric method using Folin-Ciocalteu reagent. International Organization for Standardization.

Kostić DA, Dimitrijević DS, Stojanović GS, Palić IR, Đorđević AS, Ickovski JD. 2015. Xanthine oxidase: isolation, assays of activity, and inhibition. $J$ Chem. DOI: 10.1155/2015/294858

Kraut JA, Mullins ME. 2018. Toxic alcohols. N Engl J Med 378:270-80. DOI: 10.1056/NEJMra1615295

Lai XZ, Yang YB, Shan XL. 2004. The investigation of Euphorbiaceous medicinal plants in southern China. Econ Bot 58(Suppl. 1):S307-20. DOI: 10.1663/0013-0001(2004)58[S307:TIOEMP]2.0.CO;2

Liu H-B, Zhang H, Yu J-H. 2015. New diterpenoids from Sapium discolor. $J$ Asian Nat Prod Res 17:1117-28. DOI: 10.1080/10286020.2015.1119665

Löliger J. 1991. The use of antioxidants in food. In: Free Radicals and Food Additives (Aruoma OI, Halliwell B, eds.). London: Taylor and Francis.

Ngo TV, Scarlett CJ, Bowyer MC, Ngo PD. 2017. Impact of different extraction solvents on bioactive compounds and antioxidant capacity from the root of Salacia chinensis L. J Food Quality 9305047. DOI: $10.1155 / 2017 / 9305047$

Nobakht GM, Kadir MA, Stanslas J. 2010. Analysis of preliminary phytochemical screening of Typhonium flagelliforme. Afr $J$ Biotechnol 9(11):1655-7. DOI: 10.5897/AJB10.1405 
Prat DE. 1992. Natural Antioxidant from Plant Material. In: Phenolic Compounds in Food and Their Effects on Health II: Antioxidants and Cancer Prevention (Huang M-T, Ho C-T, Lee CY, eds.). Washington: American Chemical Society.

Sabandar CW, Ahmat N, Jaafar FM, Sahidin I. 2013. Medicinal property, phytochemistry and pharmacology of several Jatropha species (Euphorbiaceae): a review. Phytochem 85:7-29. DOI: 10.1016/j.phytochem.2012.10.009

Salatino A, Salatino MLF, Negri G. 2007. Traditional uses, chemistry and pharmacology of Croton species (Euphorbiaceae). J Braz Chem Soc 18:11 33.

Seruji NMU, Khong HY, Kutoi CJ. 2012. Antioxidant, anti-Inflammatory, and cytotoxic activities of Garcinia nervosa (Clusiaceae). $J$ Chem. DOI 10.1590/S0103-50532007000100002

The Plant List Version 1.1. 2013. Available from: www.theplantlist.org. Accessed 4 Sep 2017.
Wan Zahari M, Chandrawathani P, Sani RA. 2007. Production and evaluation of medicated urea-molasses mineral blocks for ruminants in Malaysia. In: Feed Supplementation Blocks (Makkar HPS, Sánchez M, Speedy AW, eds.), pp. 213-31. Rome: Food and Agriculture Organization of the United Nations.

Yang H, Dong Y, Du H, Shi H, Peng Y, Li X. 2011. Antioxidant compounds from propolis collected in Anhui, China. Molecules 16:3444-55. DOI: $10.3390 /$ molecules 16043444

Zhang GJ, Pan QM, Zhang YL, Liao HB, Yang YQ, Hou Y, Liang D. 2018. Coumarinolignoids and taraxerane triterpenoids from Sapium discolor and their inhibitory potential on microglial nitric oxide production. $J$ Nat Prod 81(10):2251-8. DOI: 10.1021 /acs.jnatprod.8b00585

Zhang YL, Pan QM, Liao HB, Qin JK, Li N, Liang D, Zhang GJ. 2019. Coumarinolignoids and lignanoids from the stems and leaves of Sapium discolor. Fitoterapia 131:17-22. DOI: 10.1016/j.fitote.2018.12.013 